\title{
Study of female babies of women entering confinement with vaginal trichomoniasis
}

\author{
MORAG BRAMLEY \\ Special Clinic, Royal Infirmary, Sheffield
}

\section{Summary}

A series of 868 women in the last 4 weeks of pregnancy were examined for the presence of $T$. vaginalis by direct microscopy of freshly prepared wet films and by three culture methods; 32 (3.7 per cent.) were found to give positive results.

Fourteen of the mothers with trichomoniasis at confinement had female babies, and these, together with a matching fourteen controls, were examined on three occasions by identical methods and within 21 days of birth. No baby gave positive results. On statistical examination it is very unlikely that with a much larger sample the number of positive findings could have been greater than 23 per cent. This is at variance with recent Polish work.

These results suggest that neonatal infection in female babies, although a recognized clinical entity, is rare and unlikely to make any substantial contribution to the high incidence of trichomoniasis in women.

\section{Introduction}

Trichomoniasis is widely recognized as sexually transmitted in adults. The disparity in incidence between males and females has led investigators to seek other modes of transmission. Baths, bidets, W.C.s, swimming baths, and towels find little or no support as sources. The possibility of neonatal infection cannot be so lightly dismissed.

Shaw, Henrikson, Kessel, and Thompson (1952) found that 36 of 44 virgin daughters of 25 mothers with trichomoniasis harboured the parasite. The finding suggested the possibility of neonatal infestation followed by a long and variable period of latency. This was investigated by Robinson and Halifax (1961). They found 430 (48 per cent.) of 897 pregnant women with the disease and observed their babies. Trichomoniasis vaginalis was not found in any baby. A year later Komorowska,
Kurnatowska, and Liniecka (1962) reported finding the parasite in six (17 per cent.) of 35 female infants, aged 0 to 3 weeks, born to women with the disease. This has been followed by other reports from Poland. Glowinski, Golab, and Norska (1965) found that 10 per cent. of baby girls born to women with trichomoniasis were affected, and Worwag (1971) claimed to find 55 per cent. of baby girls and 29 per cent. of baby boys with the condition.

Isolated reports of babies with trichomonal infestation have been reported by Binder (1963), Zakharchenko (1966), Grys and Kwapisiewicz (1966), Littlewood and Kohler (1966), and Sander (1967). In all but the first, the mother had vaginal trichomoniasis and the disease in the baby was believed to have been contracted from the mother during delivery.

All these reports prompted the present study.

\section{Patients and methods}

The series comprised 868 antenatal patients who were within 4 weeks of their expected date of delivery. They were seen between September, 1972, and December, 1973. All were seen and tested personally, as were the babies in the study.

Included in the demographic data were age, social class of husband, and parity. Any complaint of discharge during the present pregnancy and its treatment were noted, as well as any other similar complaint and its treatment prior to this pregnancy.

Vaginal material was obtained from all women using a plastic spoon and platinum loop. Microscopy of fresh wet preparations, using saline as the diluent, was carried out immediately. As well as noting the presence or absence of trichomonads, the presence or absence of Döderlein's bacillus and other flora, including yeasts, were also observed, using both the wet preparation and Gram-stained vaginal smears.

Three types of culture media were inoculated directly in the antenatal clinic (Appendix I). These media were Oxoid trichomonas medium (Feinberg and Whittington, 1957), C.P.L. medium (Johnson 


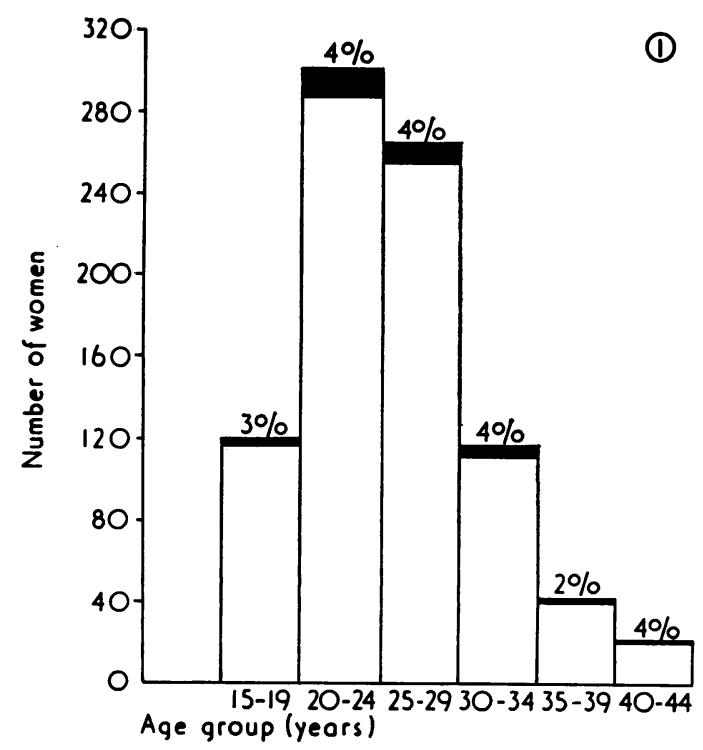

FIG. 1 Age and infection rate of mothers examined. Percentage of women in each age group who have $\mathrm{T}$. vaginalis infection is shown above each bar

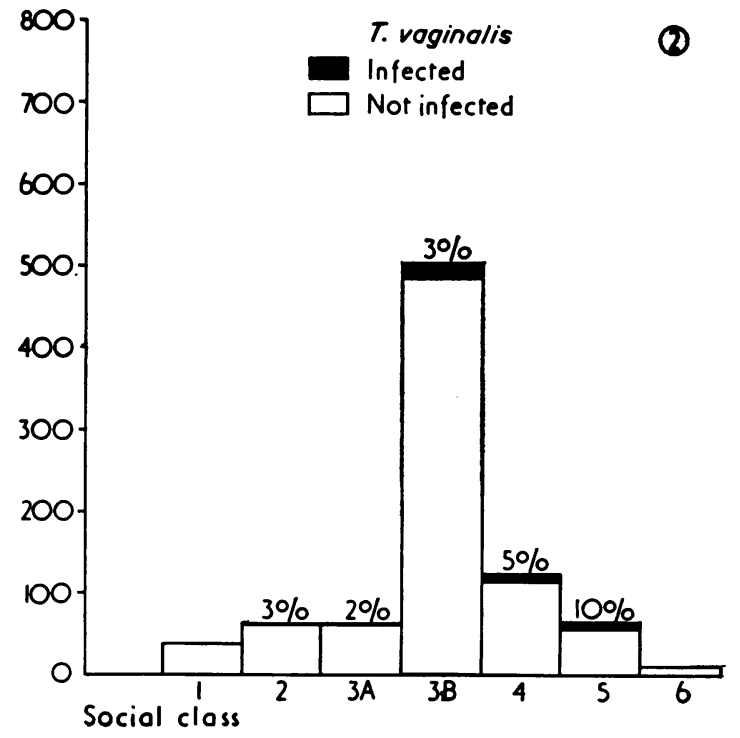

FIG. 2 Social class and infection rate of mothers examined. Percentage of mothers in each social class who have $\mathrm{T}$. vaginalis infection is shown above each bar. Registrar General's classification of occupations (1966)

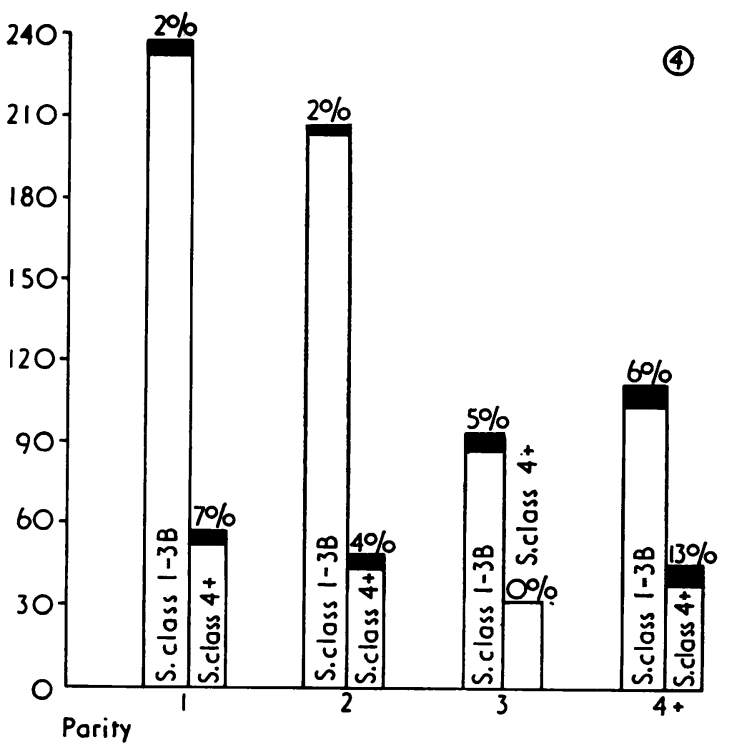

FIG. 4 Infection rate taking account of social class and parity. Percentage of mothers in each social class grouping who have $\mathrm{T}$. vaginalis infection is shown above each bar. Registrar General's classification of occupations (1966)
FIG. 3 Parity and infection rate of mothers examined. Percentage of mothers in each parity group who have $\mathrm{T}$. vaginalis infection is shown above each bar 
and Trussell, 1943), and that of Lowe (1972). Each expectant mother was tested on one occasion only.

The female babies of all women entering their confinement with vaginal trichomoniasis were examined; vaginal material was obtained by plastic spoon and platinum loop and examined by microscopy and culture on three occasions within the first 21 days of life. The mothers of these babies were each matched with a control mother of similar age, social class, parity, similar complaint of discharge, and similar previous treatment of this discharge. The control group consisted only of mothers who had female babies. The babies of these matched mothers were similarly tested.

\section{Results}

\section{MOTHERS}

Of the 868 mothers, 32 ( 3.7 per cent.) were found to harbour $T$. vaginalis. In view of a complaint of a profuse vaginal discharge one was treated before her confinement.

Figs 1 to 3 show the infestation rates according to age, social class (for details see Appendix II), and parity. The majority were aged 20 to 29 years (range 15 to 45 ). Infestation rates were significantly higher (eliminating the effect of parity) in those of social classes 4 to 6 taken as a group than in social classes 1 to 3 also taken as a group (Cochran's test: $\mathrm{P}<0.05)$ : (Cochran, 1954). This is shown taking account of parity in Fig. 4. The rate of infestation rose with parity (Fig. 3) but this could have been a chance finding.
An analysis of past history of vaginal discharge and treatment showed that 169 (19.5 per cent.) of the 868 mothers had complained of discharge and received treatment before the present pregnancy began. A further 101 (11.6 per cent.) admitted having had a discharge but had received no treatment.

As regards history of vaginal discharge during the pregnancy under study, 139 mothers $(16.0$ per cent.) had complained of this and received treatment from their own practitioners including ten with trichomonal infestation. Details of this treatment were not available. A further 281 ( 32.4 per cent.) admitted that they had an abnormal amount of discharge but had had no treatment.

Complaints of vaginal discharge were not a reliable guide to the presence or absence of $T$. vaginalis (Fig. 5). If tests had been carried out only on those with a complaint of discharge, twelve infestations (37.5 per cent.) would have escaped detection. On the other hand, if a clinical finding of abnormal discharge or vaginitis had been the criteria for testing, seven of these twelve cases would not have been

TABLE I Results of laboratory tests for $\mathrm{T}$. vaginalis in 868 pregnant women

\begin{tabular}{|c|c|c|c|}
\hline \multirow[b]{2}{*}{ Culture } & \multicolumn{3}{|c|}{ Wet film } \\
\hline & + & - & Total \\
\hline$\div$ & 21 & 3 & 24 \\
\hline- & 8 & 836 & 844 \\
\hline Total & 29 & 839 & 868 \\
\hline
\end{tabular}

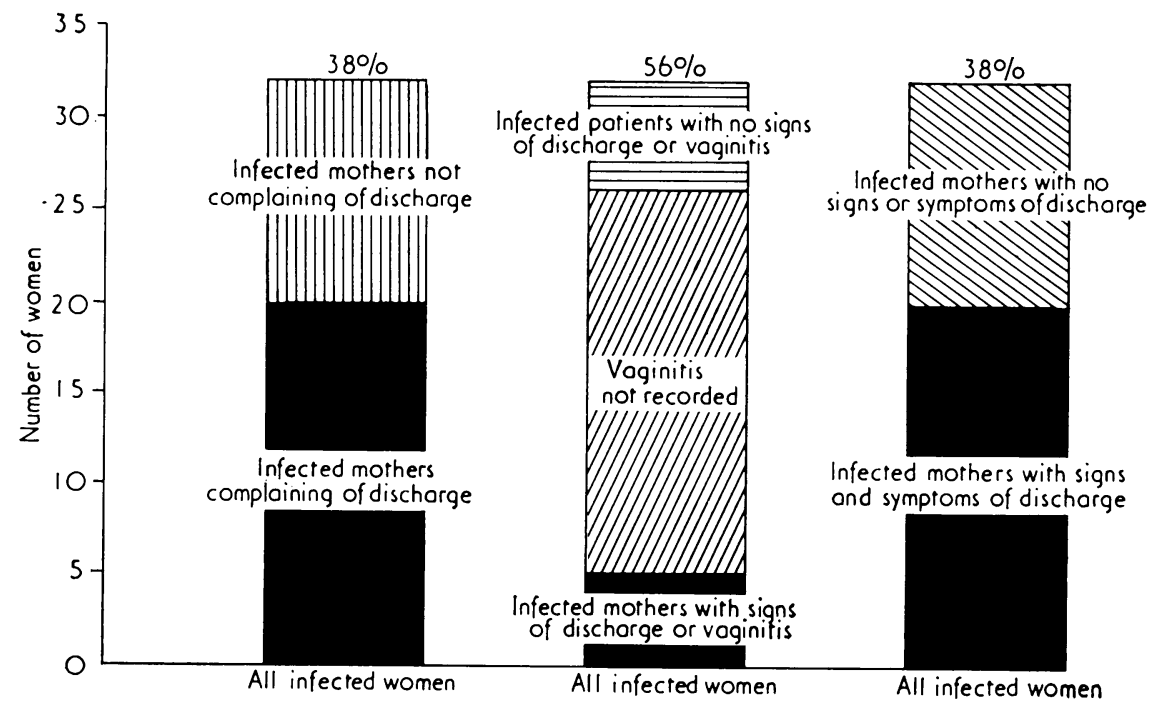

FIG. 5 T. vaginalis infections which would have been missed if only patients with signs and symptoms had been tested. Percentage of infections which would have been missed given above each bar 
discovered. This finding was based on a smaller number of patients as vaginitis was not originally recorded (See Fig. 5). If symptoms and signs had been the criteria of testing, again twelve infestations (37.5 per cent.) would have escaped detection.

Microscopy of freshly prepared wet films from the mother's vaginal material showed more positive findings than the combined culture methods (Tables I and II).

$T$. vaginalis was seen on wet film and in culture in 21 mothers, and eight had $T$. vaginalis on wet film while cultures were negative. Three cultures were positive when wet films were negative. Consequently, if culture methods only had been used, eight cases would have been missed. If microscopy of fresh wet specimens only had been used three cases would have been missed.

\section{BABIES}

Of the children born to infected mothers, seventeen (53.1 per cent.) were male and fourteen ( 43.8 per cent.) were female. One ( $3 \cdot 1$ per cent.) was still-born. There were no multiple births. The mother treated before delivery had a female child; post-partum tests on the mother showed that trichomoniasis was still present, and her child was trerefore included in the series.

For all the fourteen female babies of infected mothers, as well as those of the control group of mothers, the three examinations of vaginal material were completed within 21 days of birth. All were negative.

When these negative results on fourteen babies are examined statistically the exact 95 per cent. confidence limits for the true proportion are 0 to 23 per cent. (Geigy, 1962). In other words, even if 10,000 female babies of 10,000 mothers known to be infected at confinement were examined, the number of infected babies would lie somewhere between 0 and 23 per cent.; with such a small sample as fourteen, one cannot be dogmatic, but it appears to be at variance with the figure of 55 per cent. given by Worwag (1971).

An incidental finding was that 73 mothers with evidence of vaginal Candida albicans at predelivery testing produced twelve female babies who showed spores and/or hyphae on Gram-stained smears of vaginal material.

\section{Discussion}

The finding of only 4 per cent. positive results in this series was unexpectedly low. This may be accounted for by the past history of treatment of 308 different infections in 205 (23.6 per cent.) of the 868 patients, 139 ( 16.0 per cent.) having been treated during the pregnancy studied, by suppression of the parasite by high rates of positive findings for yeasts and hence altered $\mathrm{pH}$, and by the fact that only one series of investigations was carried out on each mother.

Cassie and Stevenson (1973), in a survey of 1,000 ante-natal cases in Glasgow, found 89 (9 per cent.) with $T$. vaginalis on one examination only. Cultures were not used. Microscopy of vaginal material accounted for 45 (50 per cent.) and Papanicolaoustained cervical smears for 76 ( 85 per cent.). The limitations of the latter method in the hands of inexperienced microscopists are well recognized. Jennison (1966), working in Manchester, found a positivity rate of less than 2 per cent. in over 7,000 antenatal cases. He used phase-contrast microscopical examination of fresh specimens from the vagina, and occasionally cultures. These examinations were done only on patients with signs or symptoms of discharge. If this patient selection had been used in the present study, 37.8 per cent. of infections would have been overlooked. In each patient Jennison (1966) carried out these investigations on one occasion, except where there was repeated complaint. As in the present study, the series of Jennison (1966) and of Cassie and Stevenson (1973) give lower percentages than might be expected. One important factor may be the widespread and growing use of metronidazole in recent years.

The negative findings in the babies is in keeping with the findings of Robinson and Halifax (1961) and is in conflict with the high rates of positivity reported from Poland (Komorowska and others, 1962; Glowinski and others, 1965; Worwag, 1971). In the Polish series more reliance was placed on Giemsastained smears than is usually accepted (Trussell, 1947). A few were examined by culture towards the end of the series reported by Komorowska and

TABLE II Results of use of individual culture media for detection of $\mathrm{T}$. vaginalis compared with direct microscopy of fresh wet preparations

\begin{tabular}{|c|c|c|c|c|c|c|c|c|c|}
\hline \multirow{3}{*}{$\begin{array}{l}\text { Culture medium } \\
\text { Culture }\end{array}$} & \multicolumn{3}{|c|}{ Oxoid trichomonas } & \multicolumn{3}{|c|}{ CPLM } & \multicolumn{3}{|c|}{ Lowe's } \\
\hline & \multicolumn{3}{|c|}{ Wet film } & \multicolumn{3}{|c|}{ Wet film } & \multicolumn{3}{|c|}{ Wet film } \\
\hline & + & - & Total & + & - & Total & + & - & Total \\
\hline+ & 6 & 1 & 7 & 7 & 2 & 9 & 6 & 0 & 6 \\
\hline- & 2 & 269 & 271 & 5 & 264 & 269 & 1 & 305 & 272 \\
\hline
\end{tabular}


others (1962). Glowinski and others (1965) used freshly prepared wet films of vaginal secretion, Papanicolaou-stained smears, and Giemsa-stained smears. Worwag (1971) did not use vaginal material from babies but examined fresh urinary sediment by phase-contrast microscopy and also used Giemsastained smears.

My thanks are due to Professor D. C. A. Bevis and Mr. R. L. Lunt for access to their patients, to Dr. A. E. Jephcott for bacteriological assistance, to Dr. R. A. Dixon for advice on statistical method, and to Dr. R. S. Morton and staff for encouragement and help.

\section{Appendix}

I. Culture Media used for Trichomonas vaginalis

(1) OXOID TRICHOMONAS MEDIUM (Feinberg and Whittington, 1957).

$\begin{array}{lr}\text { Liver digest } & 25.0 \mathrm{~g} \text {./litre } \\ \text { Sodium chloride } & 6.5 \mathrm{~g} \text {./litre } \\ \text { Dextrose } & 5.0 \mathrm{~g} \text {./litre } \\ \text { 'Ionagar' No. 2. pH } 6.4 & 1.0 \mathrm{~g} \text {./litre } \\ \text { Inactivated horse serum } & 80 \mathrm{ml} \text {./litre } \\ \text { Penicillin G } & 500 \mathrm{u} . / \mathrm{ml} / \\ \text { Streptomycin } & 500 \mu \mathrm{g} . / \mathrm{ml} .\end{array}$

This medium has recently been re-assessed (Cox and Nicol, 1973).

(2) C.P.L.M. MEDIUM (Johnson and Trussell, 1943). Liver infusion 20 per cent.

Serum 20 per cent. by volume

Ringer's solution 60 per cent.

Cysteine monohydrochloride 0.15 per cent.

Agar

Peptone

$0 \cdot 10$ per cent.

2.0 per cent. by

Maltose

0.10 per cent. weight

Methylene blue

0.002 per cent.

(3) LOWE's MRDIUM (Lowe, 1972).

Liver extract

$12.5 \mathrm{~g}$.

Sodium chloride

$2.5 \mathrm{~g}$.

Maltose

Agar

Deionized water

$0.5 \mathrm{~g}$.

$1.25 \mathrm{~g}$

Ascorbic acid (4 per cent.)

Filde's extract

Chloramphenicol

Gentamycin sulphate

Amphotericin

$0.05 \mathrm{~g}$.

$0.05 \mathrm{~g}$.

$0.0005 \mathrm{~g}$.
II. Classification of Occupations, 1966 (General Register Office, HMSO, Lond.).

\begin{tabular}{|c|c|c|}
\hline $\begin{array}{l}\text { Survey } \\
\text { Code }\end{array}$ & $\begin{array}{c}\text { Code from } \\
\text { Book }\end{array}$ & General Group \\
\hline 1 & I & Professional and managerial \\
\hline 2 & II & $\begin{array}{l}\text { Semi-professional (Teachers, } \\
\text { nurses, etc.) }\end{array}$ \\
\hline $3 \mathrm{~A}$ & III & $\begin{array}{l}\text { Skilled non-manual (Clerks, } \\
\text { typists, etc.) }\end{array}$ \\
\hline 3B & III & $\begin{array}{l}\text { Skilled manual (drivers, } \\
\text { engineering workers) }\end{array}$ \\
\hline 4 & IV & $\begin{array}{l}\text { Semi-skilled (machine operators, } \\
\text { painters) }\end{array}$ \\
\hline $\begin{array}{l}5 \\
6\end{array}$ & $\mathbf{V}$ & $\begin{array}{l}\text { Unskilled (Labourers, etc.) } \\
\text { H.M. Forces and students }\end{array}$ \\
\hline
\end{tabular}

\section{References}

BINDER, S. S. (1963) Obstet. and Gynec., 21, 354

Cassie, R., and Stevenson, A. (1973) ₹. Obstet. Gynaec. Brit. Cwlth, 80, 48

CoCHRAN, W. G. (1954) Biometrics, 10, 417

Cox, P. J., and Nicol, C. S. (1973) Brit. F. vener. Dis., 49, 536

FeinBeRG, J. G., and Whittington, J. M. (1957) $\mathcal{f}$. clin. Path., 10, 327

GrigY (1962) 'Documenta Geigy, Scientific Tables', 6th edit., p. 87. Geigy Pharmaceutical, Manchester

GeNERAL REgister OFFICE (1966) 'Classification of Occupations'. H.M.S.O., London

GlowiNSKI, M., GolaB, H., and NorsKa, I. (1965) Wiad. Lek., 18, 825

Grys, E., and KwaPisiewicz, I. (1966) Pediat. Pol., 41, 969

JeNnISON, R. F. (1966) In 'Symposium on Candida Infection', ed. Winner and Hurley, p.102. Livingstone, Edinburgh

Johnson, G., and Trussell, R. E. (1943) Proc. Soc. exp. Biol. (N.Y.), 54, 245

KOMOROWSKa, A., KURNatowska, A., and LINIECKA, J. (1962) f. Pol. Tow. Parazytol., 8, 247

LitTlewOod, J. M., and KoHLER, H. G. (1966) Arch. Dis. Childh., 41, 693

Lowe (1972) f. med. Lab. Technol., 29, 389

Robinson, S. C., and Halifax, N. S. (1961) f. Canad méd. Ass., 84, 948

SANDER, C. (1967) Z.Kinderheilk., 98, 364

Shaw, H. N., HeNRIKSEN, E., Kessel, J. F., and Thompson, C. F. (1952) Westn F. Surg., 60, 563

TRUSSELL, R. E. (1947) "Trichomonas vaginalis and Trichomoniasis", p.123. Thomas, Springfield, Ill.
Worwag, Z. (1971) Wiad. Parazytol., 17, 351, 355

ZAKHARCHENKO (1966) Bocheschanka Hospital, Ukraine 